\title{
Minimal Invasive Surgery in Newborns and Infants: Northern Cyprus Experience
}

\author{
Emil Mammadov' (1), Gönül Küçük² (1) \\ 'Department of Pediatric Surgery, Near East University School of Medicine, Nicosia, Cyprus \\ ${ }^{2}$ Clinic of Pediatric Surgery, Dr. Burhan Nalbantoğlu State Hospital, Nicosia, Cyprus
}

ORCID IDs of the authors: E.M. 0000-000I-8I43-I643; G.K. 0000-0002-35I0-8789.

Cite this article as: Mammadov E, Küçük G. Minimal Invasive Surgery in Newborns and Infants: Northern Cyprus Experience. Cyprus J Med Sci 2019; 4(3): 216-9.

\section{BACKGROUND/AIMS}

Pediatric minimal invasive surgery (MIS) is a relatively recent approach in Northern Cyprus, where it is being performed for less than a decade. This is the first study reflecting our initial experience with MIS in newborns and infants.

\begin{abstract}
MATERIAL and METHODS
The case records of all laparoscopic and thoracoscopic procedures performed on children younger than I year by two pediatric surgeons at two different hospitals (university hospital and state hospital) during 2012-2017 were collected and retrospectively analyzed. Statistical analysis was performed using SPSS version 22 for Macintosh. The descriptive statistics are presented as frequencies, percentages, and means. To determine the relationship between principal variables and other continuous variables, Pearson correlation test was used. $A$ p-value of $<0.05$ was considered statistically significant.
\end{abstract}

\section{RESULTS}

The hospital records of 18 patients [15 (83.3\%) boys and $3(16.7 \%)$ girls] were included in the study. The mean age at the time of procedure was 5 months 10 days (I day-II months). The surgical procedure was gastrointestinal in $9(50 \%)$, urologic in 5 (28\%), gynecologic in 2 (II\%), and thoracic in 2 (II\%) cases. The mean operative time was 74 (I5-355) min. The operative time and hospitalization time both showed a tendency to increase in patients who were younger, but these findings were not statistically significant. Postoperative feeding was started at a mean 1.9 (range, $0-7$ ) days. The feeding resumption time was significantly correlated with age ( $p=0.03$ ). The mean postoperative hospitalization time was 8.7 (range, $0-32$ ) days and the median was 2 days.

\section{CONCLUSION}

The initial experience from our patients shows results similar to those reported in the literature that MIS in infants is a safe and efficient option, even in low-populated countries, as long as the procedure is performed by pediatric surgeons who have completed their learning at high-volume centers.

Keywords: Infants, laparoscopy, minimal invasive surgery, pediatric surgery

\section{INTRODUCTION}

Minimal invasive surgery (MIS) refers to the procedures performed with a minimal incision or through a natural orifice using trocars, telescopes, insufflation, and specialized instruments (I). Although the initial experience with MIS in children has been reported as early as the 1970s, the real momentum started after wide adaption of this approach by pediatric surgeons in 1990s (2-4). Many pediatric procedures have been performed with favorable outcomes since then. MIS offers excellent cosmetic appearance, which is crucial in pediatric cases where incision scars have a risk of growing and deforming with age. Moreover, better functional results due to a decreased risk for intraabdominal adhesions, postoperative wound dehiscence, infection, herniation, decreased postoperative pain, and length of hospital stay mark the importance of MIS in pediatric population (5-I0). However, besides these advantages, MIS is associated with the difficulty of working in a small area, limited freedom of surgeon's hand movement, and attempt to perform the entire surgery with straight and nonrotating instruments. Some of these difficulties have recently been eliminated by robotic surgery. Nonetheless, specialized training is needed to perform MIS, and it has a steeper learning curve than open surgeries. 
Pediatric MIS is a relatively recent approach in Northern Cyprus, where it is being performed for less than a decade. This is the first study reflecting our initial experience with MIS in newborns and infants.

\section{MATERIAL and METHODS}

The study was approved by the Institutional Near East University Ethical Committee (Approval Date: 22.02.2018, Approval Number: YDU/2018/55-535).The case records of all laparoscopic and thoracoscopic procedures performed on children younger than I year by two pediatric surgeons at two different hospitals (university hospital and state hospital) during 2012-2017 were collected and retrospectively analyzed. Both pediatric surgeons had completed their MIS training at high-volume centers abroad. The cases with missing or incomplete hospital records were excluded from the study population. All surgical procedures were performed after obtaining written informed consent from the parents.

\section{Statistical Analysis}

Statistical analysis was performed using Statistical Package for the Social Sciences version 22 for Macintosh (SPSS IBM Corp.; Armonk, NY, USA). The descriptive statistics are presented as frequencies, percentages, and means. To determine the relationship between principal variables and other continuous variables, Pearson correlation test was used. A $p$-value of $<0.05$ was considered statistically significant.

\section{RESULTS}

The hospital records of 18 patients [15 (83.3\%) boys and 3 (16.7\%) girls] were included in the study. The mean age at the time of the procedure was 5 months 10 days (I day-II months). The surgical procedure was gastrointestinal in $9(50 \%)$, urologic in 5 $(28 \%)$, gynecologic in $2(11 \%)$, and thoracic in $2(11 \%)$ cases. The indications for surgery are listed in Table I. The most frequent indication for MIS in our study population was nonpalpable testis (4 patients, 22.2\%). Furthermore, the two most frequent MISs performed in our study group were diagnostic laparoscopy ( 4 patients, 22.2\%) and gastrostomy placement (3 patients, $16.5 \%$ ) (Table 2). Of the 4 patients undergoing diagnostic laparoscopy, 3 were those with a nonpalpable testis. Among the 4 patients with a nonpalpable testis, 3 had a vanishing testis, and excision of the nubbin was performed for them; the remaining I patient

\begin{tabular}{|lcc|}
\hline TABLE I. Indications for minimal invasive surgery & \\
\hline Surgical indication & $\mathbf{n}$ & (\%) \\
\hline Adnexal torsion & 2 & II.I \\
Oral feeding difficulties & 2 & II.I \\
Congenital diaphragmatic hernia & 2 & II.I \\
Hirschsprung disease & 2 & II.I \\
Intestinal obstruction & I & 5.6 \\
Intussusception & 2 & 11.1 \\
Esophageal atresia & I & 5.6 \\
Cholelithiasis & I & 5.6 \\
Ureteropelvic junction obstruction & I & 5.6 \\
Nonpalpable testis & 4 & 22.2 \\
Total & 18 & 100 \\
\hline
\end{tabular}

had intraabdominal testis, and single-stage laparoscopic orchidopexy was performed for this patient. Laparoscopic gastrostomy placement was performed in 2 patients with oral feeding difficulties due to neurological impairment and I patient with isolated esophageal atresia. The mean operative time was 74 (15-355) min. There were 2 unintended conversions to open surgery. One was due to hemodynamic instability and ventilation difficulty during thoracoscopic diaphragmatic repair, and the other was a failed laparoscopic reduction attempt at intussusception. Postoperative complication developed in only patient in our study group; it included early postoperative collection and wound dehiscence in the 3-mm port incision site. This condition resolved spontaneously with conservative management. No obvious bleeding incident occurred during surgery in all patients. Excluding I patient who was hospitalized for 6 months due to conditions unrelated to laparoscopy, the mean postoperative hospitalization time was 8.7 (range, $0-32$ ) days and the median was 2 days. The operative time and hospitalization time both showed a tendency to increase in patients who were younger, but these findings were not statistically significant. Postoperative feeding was started at a mean 1.9 (range, 0-7) days. The feeding resumption time was significantly correlated with age $(p=0.03)$.

\section{DISCUSSION}

Today, in the era of MIS, pediatric laparoscopy has become widely popular. Pediatric MIS is being utilized in many centers worldwide as a primary approach for abdominal and thoracic surgical pathologies. The momentum gained by MIS in mid1990s has led the pediatric surgery community to research and develop novel techniques for known problems. The application of MIS in neonates and infants dates from the late 1990s and has come a long way since then $(7,|1-| 4)$. Surgical procedures in small children, infants, and neonates require additional skills from both surgical and anesthesia teams. First, the surgeon has to work in a smaller cavity; this complicates the approach, especially in complex procedures requiring intracorporeal suturing. At the same time, prolonged operative time and surgeon fatigue increase the risk for inadvertent tissue and organ injuries. The anesthetic management in these cases poses special problems due to the pneumoperitoneum created and extremes of position adopted in addition to the fact that pediatric anesthesia itself is a challenge. Mostly the physiological

\section{TABLE 2. Surgical procedures}

\begin{tabular}{lcc} 
Surgical indication & $\mathbf{n}$ & (\%) \\
\hline Diagnostic laparoscopy & 4 & 22.2 \\
Gastrostomy placement & 3 & 16.5 \\
Thoracoscopic diaphragmatic hernia repair attempt & 2 & II.I \\
Adnexal cystic mass removal & 2 & II.I \\
Intussusception reduction attempt & 2 & II.I \\
Cholecystectomy & I & 5.6 \\
Laparoscopy-assisted transanal endorectal pull-through & I & 5.6 \\
Ladd procedure and extramucosal intestinal biopsy & I & 5.6 \\
Orchidopexy & I & 5.6 \\
Anderson-Hynes pyeloplasty & I & 5.6 \\
Total & 18 & 100
\end{tabular}


and anesthetic considerations are the same, except that child is not a small adult (I5). As for the anesthesia team, the smaller abdominal volume may predispose the patient to ventilation difficulties during gas insufflation. Moreover, pressure changes across the gas container, insufflator, and patient's thorax / abdomen cause cooling due to the Jewel-Thompson effect; this issue is especially important in neonates, who are prone to hypothermia.

Minimal invasive surgery should be performed by experienced surgeons at dedicated centers; the training itself requires a steeper learning curve than open surgery. MIS does not always imply minimal harm to the patient. Prolonged operation room stay, prolonged exposure to anesthesia, and inadvertent damage to the adjacent structures are only some of the risks that patients face in the inexperienced hands. A study by Oomen et al. (16) has shown that surgical complications decrease dramatically from $31.5 \%$ to $11.4 \%$ after the first 35 laparoscopic pyloromyotomies performed during the learning curve. Cusick et al. (I7) have shown that the learning curve for laparoscopic splenectomy reaches a plateau after the initial 20 cases. The evidence from the literature highlights the importance of working and training at high-volume centers, and this is probably the most important challenge that surgeons in low-populated areas have to overcome.

A laparoscopic approach offers several advantages over open procedures: I) it potentially reduces the surgical stress and fluid shifts that may accompany it; 2 ) it is associated with a less need for postoperative analgesia and with reduced postoperative respiratory and wound complications; 3) it shortens postoperative convalescence, including the intensive care unit stay; and 4 ) it is associated with a rapid return to normal diet and with a decreased overall hospital stay (18). Although being quite recent, the results in our series show favorable outcomes regarding intraoperative and postoperative complications associated with MIS. Only I patient (5.6\%) developed a minor wound complication, which resolved with conservative management. Two patients needed conversion to open surgery. Feeding resumption in our group was significantly correlated with age, with a shorter feeding resumption time observed in older babies. The reason for this correlation was that the surgery performed in these patients mostly comprised diagnostic laparoscopy and urologic procedures. The mean feeding resumption time observed in this study seems long ( 8.7 days), but due to the variability of the procedures in this series, we prefer to accept the median feeding resumption time of 2 days. Although statistically insignificant, hospitalization time observed in this study also showed a tendency to increase with a younger age; this was again related to the complexity of the procedures performed in smaller children. The operative time also varied greatly $(74 \pm 89 \mathrm{~min})$ due to the diversity of the cases within the study group. Overall, the initial experience from our patients shows results similar to those reported in the literature that MIS in infants is a safe and efficient option, even in low-populated countries, as long as it is performed by pediatric surgeons who have completed their learning at high-volume centers. The pediatric surgeons who work in these regions should use the opportunities to follow the innovations and continue their education. They should safely and effectively use MIS in children, as it is widely used across the world and has become the gold standard for most of the surgeries.

Ethics Committee Approval: Ethics committee approval was received for this study from Near East University Ethics Committee (Approval Date: 22.02.2018, Approval Number: YDU/2018/55-535).

Informed Consent: Written informed consent was obtained from the parents of the patients who participated in this study.

Peer-review: Externally peer-reviewed.

Author contributions: Concept - E.K, G.K; Design - E.K, G.K.; Supervision - E.K, G.K.; Resource - E.K, G.K.; Materials - E.K, G.K; Data Collection and/or Processing - E.K, G.K; Analysis and/or Interpretation - E.K, G.K; Literature Search - E.K, G.K; Writing - E.K, G.K.; Critical Reviews - E.K, G.K.

Conflict of Interest: The authors have no conflicts of interest to declare.

Financial Disclosure: The author declared that this study has received no financial support.

\section{REFERENCES}

I. Blinman T, Ponsky T. Pediatric minimally invasive surgery: laparoscopy and thoracoscopy in infants and children. Pediatrics 2012; 130(3): 539-49. [CrossRef]

2. Gans SL, Berci G. Peritoneoscopy in infants and children. J Pediatr Surg 1973; 8(3): 399-405. [CrossRef]

3. Kleinhaus S, Hein K, Sheran M, Boley SJ. Laparoscopy for diagnosis and treatment of abdominal pain in adolescent girls. Arch Surg 1977; II2(10): II78-9. [CrossRef]

4. Holcomb GW 3rd, Olsen DO, Sharp KW. Laparoscopic cholecystectomy in the pediatric patient. J Pediatr Surg 199|; 26(I0): ||86-90. [CrossRef]

5. Schier F. Pediatric laparoscopy current state and future. Indian Pediatr 1994; 3I(2): II5-20.

6. Jawad AJ, Kurban K, el-Bakry A, al-Rabeeah A, Seraj M, Ammar A. Laparoscopic cholecystectomy for cholelithiasis during infancy and childhood: cost analysis and review of current indications. World J Surg 1998; 22(I): 69-73. [CrossRef]

7. Decker PA, Chammas J, Sato TT. Laparoscopic diagnosis and management of ovarian torsion in the newborn. JSLS 1999; 3(2): I4I-3.

8. Fujimoto T, Segawa O, Lane GJ, Esaki S, Miyano T. Laparoscopic surgery in newborn infants. Surg Endosc 1999; 13(8): 773-7. [CrossRef]

9. Geisler DP, Jegathesan S, Parmley MC, McGee JM, Nolen MG, Broughan TA. Laparoscopic exploration for the clinically undetected hernia in infancy and childhood. Am J Surg 200I; 182(6): 693-6. [CrossRef]

10. Mansuria SM, Sanfilippo JS. Laparoscopy in the pediatric and adolescent population. Obstet Gynecol Clin North Am 2004; 3I(3): 469-83. [CrossRef]

II. Doede T, Hoffmann K, Graffmann-Weschke K, Waldschmidt J. Laparoscopy in the newborn infant--indications and procedure. Langenbecks Arch Chir Suppl Kongressbd 1998; II5: 120-3.

12. Jawad AJ, Al-Meshari A. Laparoscopy for ovarian pathology in infancy and childhood. Pediatr Surg Int 1998; 14(I-2): 62-65. [CrossRef]

13. Kandpal DK, Prasad A, Chowdhary SK. Laparoscopic and thoracoscopic gastric pull-up for pure esophageal atresia in early infancy. $J$ Indian Assoc Pediatr Surg 2013; I8(I): 27-30. [CrossRef]

14. Kutikov A, Resnick M, Casale P. Laparoscopic pyeloplasty in the infant younger than 6 months--is it technically possible? J Urol 2006; 175(4): 1477-9. [CrossRef] 
15. Gupta R, Singh S. Challenges in paediatric laparoscopic surgeries. Indian J Anaesth 2009; 53(5): 560-6.

16. Oomen MW, Hoekstra LT, Bakx R, Heij HA. Learning curves for pediatric laparoscopy: how many operations are enough? The Amsterdam experience with laparoscopic pyloromyotomy. Surg Endosc 2010; 24(8): 1829-33. [CrossRef]
17. Cusick RA, Waldhausen JH. The learning curve associated with pediatric laparoscopic splenectomy. Am J Surg 200l; |8|(5): 393-7. [CrossRef]

18. Pretorius M, Rasmussen GE, Holcomb GW. Hemodynamic and catecholamine responses to a laparoscopic adrenalectomy for pheochromocytoma in a pediatric patient. Anesth Analg 1998; 87(6): 1268-70. [CrossRef] 